\title{
Effect of Liquid Physical Properties and Flow Rates on the Surface Area of Sprays from a Pressure Atomizer
}

\section{J. A. CONSIGLIO and C. M. SLIEPCEVICH}

University of Michigan, Ann Arbor, Michigan

The effects of the physical properties and volume flow rate of liquids on the surface area of sprays produced by a pressure type of atomizing nozzle were determined experimentally. The specific surface area of the sprays is correlated by an equation of two dimensionless groups in terms of the variables surface tension to the -1.0 power, kinematic viscosity to the -0.4 power, and volume flow rate to the 2.4 power. The volume flow rate is correlated by an equation of two dimensionless groups containing the variables viscosity to the 0.17 power, density to the -0.58 power, and spray pressure to the 0.42 power. The conversion of compression energy to surface-area energy appears to be constant at approximately $0.1 \%$.

The purpose of this investigation was to determine the effect of physical properties and flow rates of liquids on the surface area of sprays produced by a commercial pressure type of atomizer by means of an optical sampling technique developed by Gumprecht and Sliepcevich $(1,2)$. This technique is based on the light-scattering properties of spherical particles. The method consists of measuring continuously the intensity of the transmitted light beam through a dispersion of droplets as they settle differentially under the influence of gravity through a known settling distance. The size distribution of the spray is calculated from the light-intensity measurements by means of a modified form of the LambertBeer transmission equation and Stokes's Law. The size of the spray chamber employed and the turbulence generated in the chamber during the spray period restrict the use of the technique to drops $40 \mu$ or less in diameter. The changes in the drop-size distribution of the spray caused by the turbulence during the

J. A. Consiglio is at present with General Electric Company, Schenectady, New York, and C. M Oklahoma. spray period are corrected for by an empirical procedure of extrapolation to zero volume sprayed. The surface area for drops greater than $40 \mu$ is estimated by means of an empirical distribution equation.

The specific surface area of the sprays is correlated as a function of the physical properties and volume flow rate of the liquid. The volume flow rate is correlated as a function of the spray pressure and the physical properties of the liquid.

The optical sampling technique was selected in preference to the more common sampling techniques in order to avoid the large sampling errors inherent in mechanical devices such as slides, cups, and probes. These errors are dependent on the size of the drops, the size and shape of the sampling device, and the flow pattern at the sampler (5), and the magnitude of the error is difficult to predict primarily because the flow pattern is not always known.

\section{EXPERIMENTAL EQUIPMENT}

A block diagram of the experimental equipment is shown in Figure 1. The components of the equipment are a spray chamber, a pump unit to supply liquid to the nozzle, a constant-intensity light source, and an optical and electrical system to measure and record the intensity of the light beam transmitted through the dispersion of drops undergoing settling in the spray chamber.

The spray chamber, constructed of $1 / 2$-in. plywood, is 3 by 3 by $10 \mathrm{ft}$., with a volume of 2.55 by $10^{6} \mathrm{cc}$. The floor area of the chamber is covered by a removable drawboard. The settling height from the top of the chamber to the light beam is 279 $\mathrm{cm}$. and the length of the path of the light beam through the dispersion of drops in the chamber is $89.5 \mathrm{~cm}$.

The pump unit, shown in Figure 2, is capable of delivering a maximum volume of $350 \mathrm{cc}$. at a maximum rate of $32 \mathrm{cc} . / \mathrm{sec}$. at pressures up to $3,000 \mathrm{lb}$./sq. in. The volume of liquid delivered to the nozzle is determined by the position of a calibrated, adjustable screw stop in the positive displacement cylinder. Mercury is used as an intermediate fluid to prevent contamination of the liquid being sprayed by the oil.

The light source consists of a 6-volt automobile-headlight bulb. It is modulated at a frequency of 300 cycles/sec. by means of a rotating perforated disk having ten $5 / 8$-in. holes equally spaced on a 4 in.-diam. circle. An essentially parallel and monochromatic light beam is obtained by means

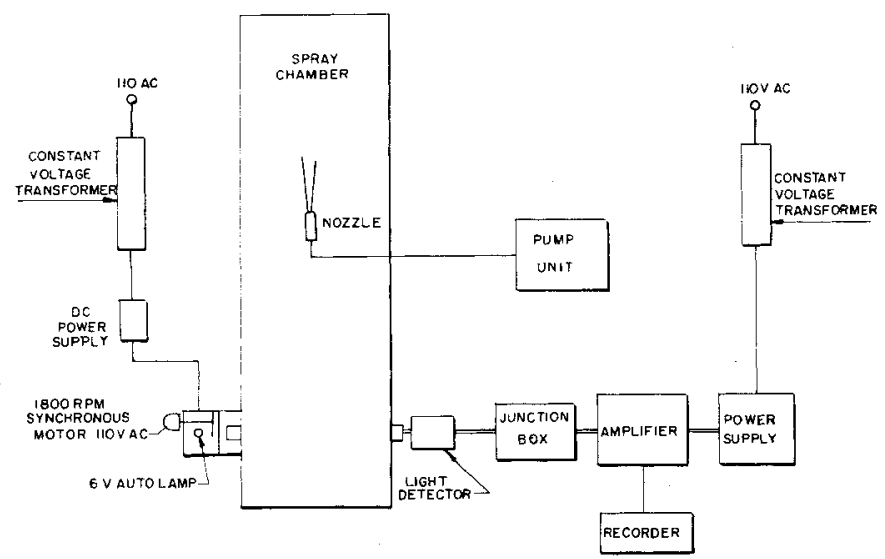

Fig. 1. Block diagram of equipment.

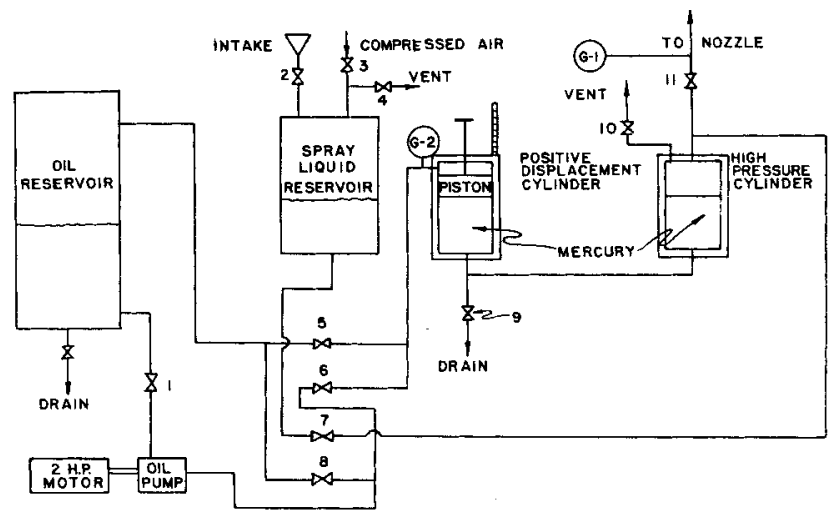

Fig. 2. Pump unit. 


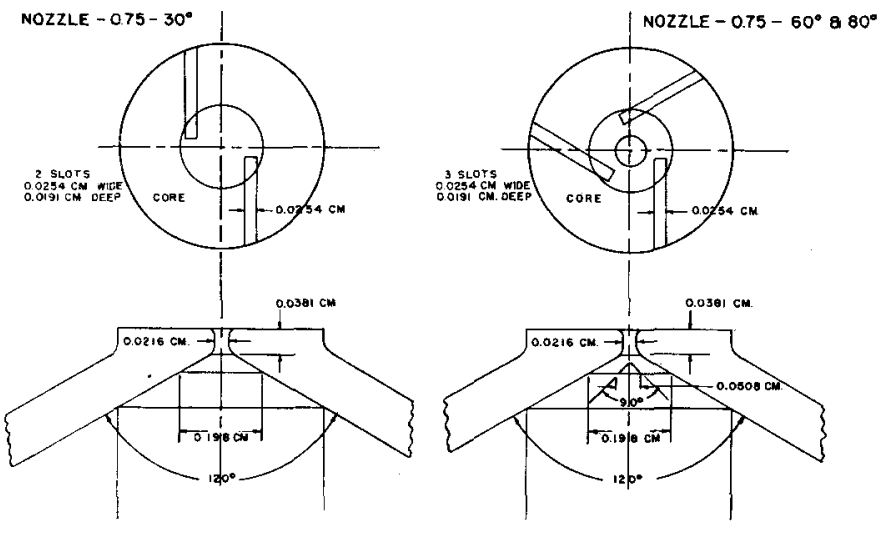

Fig. 3. Dimensional sketch of nozzles.

of a collimating lens system and interference type of filter which has a peak transmission at $4,700 \AA \pm 50 \AA$.

The light detector consists of a lenspinhole optical system which focuses the light beam on the cathode of a type-929 vacuum phototube. The half angle of the cone which the detector subtends with the drops at any point in the light beam is $0.92^{\circ}$. The a.c. signal developed by the phototube is amplified and then rectified to a d.c. voltage, which is applied to a strip-chart recorder. The deflection of the recorder is a linear function of the intensity of the light beam focused onto the phototube.

\section{EXPERIMENTAL PROCEDURE}

Determination of the drop-size distribution of sprays by the light-seattering method requires two types of measurements, the continuous measurement of the intensity of the light beam transmitted through the dispersion of spray drops setting in the chamber and the measurement of the amount of liquid that drops out of the system during the spray period.

Prior to a run the chamber is saturated by spraying liquid into the closed chamber and allowing the drops to settle to the floor of the chamber. A light-transmission run is made by spraying a known volume of liquid into the chamber and continuously recording the intensity of the light beam transmitted through the dispersion as the drops settle differentially after the spray period.

The amount of liquid that drops out of the system during the spray period is determined by collecting and weighing the liquid on a tared piece of absorbent paper placed on the removable drawboard at the bottom of the chamber. For each liquid and flow rate a series of light-transmission and drop-out runs is made by varying the volume of liquid sprayed into the chamber.

Three pressure-type swirl-chamber nozzles manufactured by the Kopp Nozzle Products Company were used. The majority of the runs were made with a nozzle rated by the manufacturer at $0.75 \mathrm{gal}$. of water $/ \mathrm{hr}$. and $60^{\circ}$ cone angle when spraying at a pressure of $100 \mathrm{lb} . / \mathrm{sq}$. in. One liquid, water, was sprayed with two other nozzles of the same rated capacity but having rated cone angles of $30^{\circ}$ and $80^{\circ}$ respectively. Sketches of these nozzles and dimensions given by the manufacturer are shown in Figure 3. The measured dimensions for the orifice diameters are given in Table 5 .

Six liquids were used in this study, the physical properties and volume flow rates of which are given in Table 1. Atomization was achieved for all liquids and flow rates reported in the study; the minimum spraying pressure used being $500 \mathrm{lb}$./sq. in.

\section{THEORY}

The intensity of a parallel monochromatic light beam $I$ which passes through a dispersion of heterogeneous drop sizes of diameter $D$ is given by the following equation ( $(2)$ :

$\ln I=\ln I_{0}-\frac{\pi l}{4} \int_{0}^{\infty} R K_{t} N D^{2} d D(1)$

The ratio between the total scattering cross section and the geometric cross section of the drop $K_{t}$ is known as the Mie theory total scattering coefficient (7). The total scattering coefficient is a complex function of the drop size, the refractive index of the drop with respect to the surrounding medium, and the wave length of the incident beam as shown in Figure $7(3,7)$. The term $R$, a correction factor to the total scattering coefficient, expresses the fraction of the total amount of light scattered by a drop which is excluded from the view of the light-measuring device ( $(2)$. In general $R$ is a function of the half angle $\theta$, which the device subtends with the drops; the parameter $\alpha$ (circumference of the drop divided by the wave length of the incident light); and the relative refractive index. $N$ is the derivative with respect to $D$ of the cumulative drop-size distribution function per unit volume of dispersion. (The dimensions of $N$ are length ${ }^{-4}$.)

For a dispersion of drops undergoing differential settling under tranquil conditions, the size range of drops removed from the path of the light beam during an interval of time $t$ can be computed from Stokes's Law:

$$
D=k t^{-1 / 2}
$$

Differentiation of Equation (1) with respect to time and substituting for $D$ in terms of time yields

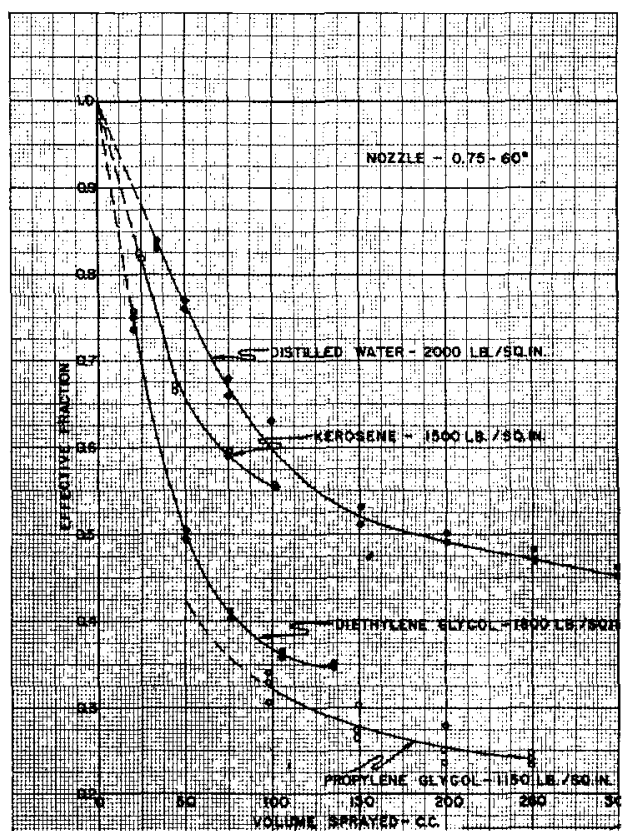

Fig. 4. Effective fraction vs. volume sprayed.

$$
R K_{t} N=\frac{8}{\pi l k^{3}} \vec{I}\left(\frac{d I}{d t}\right) t^{5 / 2}
$$

The quantity $R K_{t} N$ can be calculated from the light-transmission data of $I$ vs. $t$ at any time $t$. For a known settling height the diameter $D$ can be calculated from Stokes's Law at any time $t$. Therefore, the term $R K_{t} N$ is obtained as a function of the drop diameter $D$. Finally, since $R$ and $K_{t}$ are known functions of $D, N$ can be calculated as a function of $D$ to obtain the size-frequency-distribution curve. The surface- and volumedistribution curves are obtained by multiplying the ordinate of the sizefrequency curve by the square and cube of the corresponding diameter respectively. Equations (2) and (3) are valid provided that (1) the drops are initially uniformly dispersed throughout the volume of the system, (2) settling is under tranquil conditions, and (3) there is no interception, coalescence, or evaporation of drops during the settling process. For the concentration of drops encountered in this study, the effects of multiple scattering are negligible.

In practice it is difficult to produce a heterogeneous dispersion of drops that is initially uniformly dispersed and to fulfill the condition required by Equation (3) that the drops settle under tranquil conditions. The turbulence generated in the chamber during the spray period by the high-velocity jet emerging from the spray nozzle provides the mixing action necessary to disperse the drops formed by the nozzle throughout the volume of the chamber. Observations of the drops by means of a Tyndall beam indicated that essentially tranquil conditions are obtained in the chamber within 45 to $60 \mathrm{sec}$. from the end of the spray period. 


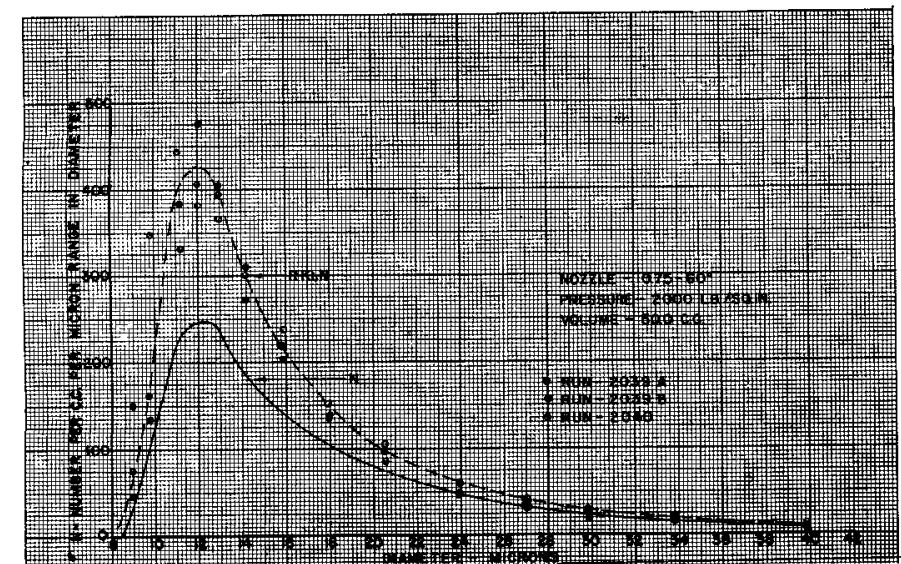

Fig. 5. Size-frequency distribution curve for water.

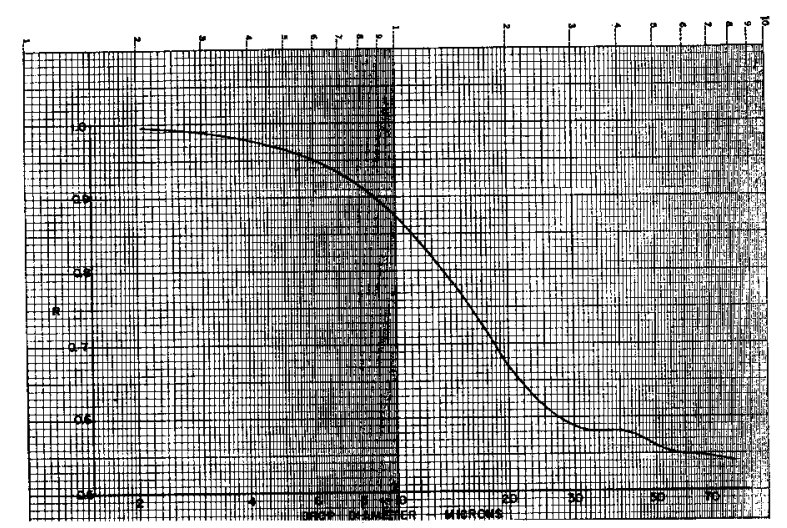

Fig. 6. $R$ vs. $D$ for $\theta=0.92^{\circ}, \lambda=0.47 \mu$.

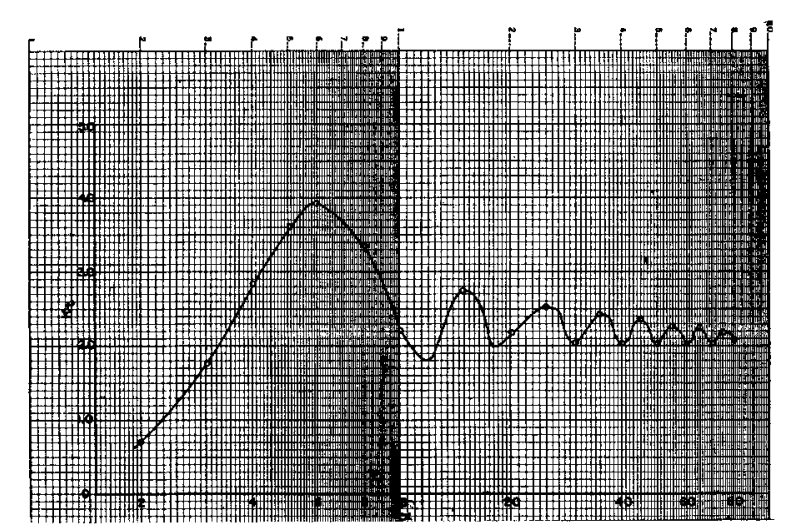

Fig. 7. The scattering coefficient as a function of $\alpha$ for water.

For the purposes of computation, zero settling time was taken as the time at which spraying ceased and Stokes's Law was assumed to be valid for drops up to $40 \mu$ in diameter.

The turbulence during the spray period causes some attenuation of all drop sizes owing to coalescence, impingement on the walls of the chamber, and evaporation. In addition, drops are lost by settling to the bottom of the chamber during the spray period. The extent of these phenomena for a given spray condition is a function of the spraying time or the volume sprayed. Thus, the observed drop-size distribution after the completion of the spray period depends on the volume sprayed or time of spraying; however, it is not implied that the drop-size distribution produced by the nozzle depends on the volume sprayed. A dependence of size distribution on volume sprayed exists only during the initial transient period at spray start-up, the time involved here is only a fraction of a second, which is negligible when compared with spraying times varying from 16 to $150 \mathrm{sec}$. The size, surface, and volume-frequency distribution curves calculated from the light-transmission data for the various volumes sprayed for a given spray condition must therefore be corrected for the changes in drop sizes that occur during, and as a result of, the spray period.

An empirical procedure based on the drop-out measurements previously described was developed to make the required correction. These measurements provide a quantitative measure of the mass of liquid that drops out of the system during the spray period as a function of the volume sprayed. A mass balance for the system during the spray period is written as follows:

(mass sprayed) $=$ (mass in suspension) + (mass impinging on walls) + (mass that drops out) + (mass evaporated)

$m_{s}=m_{i s}+m_{w}+m_{d}+m_{e}$

Equation (4) rearranged with all measurable quantities on one side of the equation becomes

$\frac{m_{s}-m_{d}}{m_{s}}=\frac{m_{i s}+m_{w}+m_{e}}{m_{s}}$

The term on the left-hand side of equation is defined as the effective fraction. A few typical experimental curves illustrating the relationship between the effective fraction and the volume sprayed are shown in Figure 4. It is noted that the effective fraction approaches unity as the volume sprayed approaches zero and by extrapolation the curves appear to intersect the ordinate at an effective fraction of unity for zero volume sprayed. Experimental measurements of the mass of liquid that drops out of the system during the spray period indicate that the drop out approaches zero as the mass sprayed approaches some small value $\epsilon$. The numerator of the right side of Equation (5) must also approach $\epsilon$ as the mass sprayed approaches $\epsilon$. A consideration of the physical significance of the terms in the numerator and the experimental conditions leads to the following conclusions. As the mass sprayed approaches $\epsilon$, there is insufficient turbulence generated in the chamber to deposit liquid on the walls of the chamber, and the term $m_{w}$ approaches zero.

The mass that evaporates from the drops approaches $\chi \epsilon$ as $m_{s}$ approaches $\epsilon$, where $\chi$ is some small fraction of $\epsilon$. Therefore, the mass remaining in suspension $m_{i s}$, approaches $\epsilon(1-\chi)$ as $m_{s}$ approaches $\epsilon$. Experimental evidence, given under Results, indicates that the atmosphere of the chamber is saturated by spraying before a series of runs is made and that the magnitude of the evaporation term is negligibly small.

The changes in drop-size distribution caused by coalescence or interception 
during the spray period are a function of (1) the degree of turbulence during the spray period, (2) the product of the concentrations of the drops undergoing eoalescence or interception, and (3) the size of these drops. Decreasing the mass sprayed, and therefore the concentration of drops, reduces the changes in drop size caused by coalescence or interception to a negligible factor as the mass sprayed approaches zero. These factors as well as the changes in drop size caused by coalescence or interception during the differential settling period are discussed briefly under Results.

Thus, at an effective fraction of one the changes in drop-size distribution that occur during the spray period as a result of coalescence or interception, impingement on the walls, and drop out are minimized. The effect of evaporation is minimized by saturating the chamber prior to an experiment.

In the present investigation it was desired to characterize the spray in terms of the specific surface area. The specific surface area for drops up to $40 \mu$ in diameter for the various volumes sprayed at a given spray condition is obtained by integrating the surface-frequency distribution curves. The correction to the specific-surface-area values for drops up to $40 \mu$ in diameter is made by plotting those values against their corresponding effective fractions and extrapolating the curve to effective fraction equal to 1. For the liquids and operating conditions studied, the relationship between the specific surface area and the effective fraction is found to be linear.

The specific surface area of drops greater than $40 \mu$ is estimated by the following empirical procedure. The volume-frequency distribution curves for each volume sprayed in a series of runs for the same liquid and spray pressure are integrated to obtain the volumefraction curves as a function of the drop diameter. The volume fraction is defined as the volume of spray drops up to a given drop diameter per unit of volume sprayed. A cross plot is then made of the values of the volume fraction for various constant drop diameters vs. the effective fraction corresponding to the volume sprayed. The values of the volume fraction at a constant drop diameter are found to be linear functions of the effective fraction and are readily extrapolated to effective fraction equal to 1 to correct for the changes in drop sizes that occur during the spray period. For the liquids investigated, the logarithm of the corrected volume fraction is a linear function of the reciprocal of the diameter in the region between 15 and $40 \mu$.

It was assumed that the logarithm of the corrected volume fraction for drop diameters greater than $40 \mu$ continued as a linear function of the reciprocal of the diameter. Drop-size data reported by other investigators $(4,9,13)$ for different
TABLE 1

Liquid Physical Properties and Flow Rates

$\begin{array}{lcccccr}\text { Liquid and nozzle } & \begin{array}{c}\mu, \\ \mathrm{cp} .\end{array} & \begin{array}{c}\rho, \\ \text { g./ce. }\end{array} & \begin{array}{c}\gamma, \\ \text { dynes/cm. }\end{array} & \begin{array}{c}\text { Refractive } \\ \text { index }\end{array} & \begin{array}{c}\text { Volume } \\ \text { rate, } \\ \text { cc./sec. }\end{array} & \begin{array}{c}\text { Spray } \\ \text { pressure } \\ \text { lb./sq. }\end{array} \\ \text { Distilled water } & & & & & & \\ \text { Nozzle 0.75-30 deg. } & 0.91 & 1.0 & 70.0 & 1.33 & 1.83 & 2,000 \\ \text { Nozzle 0.75-60 deg. } & 0.91 & 1.0 & 70.0 & 1.33 & 2.10 & 2,000 \\ \text { Nozzle 0.75-80 deg. } & 0.91 & 1.0 & 70.0 & 1.33 & 2.04 & 2,000 \\ \text { Nozzle 0.75-60 deg. } & & & & & & \\ \text { Kerosene } & 1.63 & 0.807 & 28.0 & 1.52 & 1.53 & 700 \\ & 1.68 & 0.808 & 28.0 & 1.52 & 2.07 & 1,500 \\ \text { Butyl cellosolve } & 2.99 & 0.900 & 29.9 & 1.42 & 2.10 & 1,400 \\ & 2.99 & 0.900 & 29.9 & 1.42 & 2.49 & 2,100 \\ \text { Ethylene glycol } & 17.8 & 1.112 & 50.0 & 1.43 & 2.52 & 1,400 \\ & 17.8 & 1.112 & 50.0 & 1.43 & 2.90 & 2,000 \\ \text { Diethylene glycol } & 29.1 & 1.118 & 47.5 & 1.43 & 3.10 & 1,800 \\ \text { Propylene glycol } & 45.5 & 1.034 & 38.0 & 1.43 & 2.96 & 1,150\end{array}$

nozzles also exhibit a linear relationship between the logarithm of the volume fraction and the reciprocal of the diameter in the region of larger drop diameters.

The analytical expression for the linear relationship between the logarithm of the volume fraction and the reciprocal of the drop diameter is

$$
\frac{V_{D}}{V}=e^{(a / D+b)}
$$

The volume of drops up to any diameter in terms of the volume-frequency distribution curve is

$$
V_{D}=\frac{\pi}{6} \times 10^{-12} V_{c} \int_{0}^{\infty} N D^{3} d D
$$

Substituting for $V_{D}$ from Equation (7) in Equation (6), differentiating with respect to $D$, and dividing by the density of the liquid $\rho$ gives:

$$
\begin{aligned}
& \frac{\pi \times 10^{-8} V_{e} N D^{2} d D}{V \rho} \\
& =\frac{-6 \times 10^{4} a e^{b} e^{a / D} d D}{\rho D^{3}}
\end{aligned}
$$

Since the integral of the left-hand side of Equation (8) is equal to the specific surface area, the specific surface area of drops greater than $40 \mu$ in diameter is obtained by integrating Equation (8) between the limits of $D$ equal to $40 \mu$ and $D_{m}$.

$$
\begin{aligned}
S_{>40}= & \frac{6 \times 10^{4} e^{b}}{\rho} \\
& \cdot\left[e^{a / D}\left(\frac{1}{D}+\frac{1}{a}\right)\right]_{D=40}^{D-D_{n}}
\end{aligned}
$$

\begin{tabular}{|c|c|c|c|c|c|c|c|c|c|c|c|}
\hline \multirow{2}{*}{\multicolumn{3}{|c|}{$\begin{array}{l}\text { Nozzle: } 0.75-60 \mathrm{deg} . \\
\text { Run } \\
\text { Elapsed }\end{array}$}} & & \multirow{2}{*}{\multicolumn{4}{|c|}{$\begin{array}{l}\text { Pressure: } 2,000 \mathrm{lb} . / \mathrm{sq} . \text { in. } \\
2,039 \mathrm{~A}\end{array}$}} & \multicolumn{4}{|c|}{$\begin{array}{c}\text { Volume sprayed: } 50.0 \mathrm{ce} . \\
2,039 B \quad 2,040\end{array}$} \\
\hline & & & & & & & & & & & \\
\hline time, & Deflect & on & & $1 / 2$ & $5 / 2$ & & & & & & $D, \mu$ \\
\hline sec. & $M$ & $\begin{array}{l}t \\
\text { sec. }\end{array}$ & $\begin{array}{l}t_{a v g} \\
\text { sec. }\end{array}$ & $t_{a v g}$ & $t_{a v g} \times 10^{-4}$ & $\Delta M$ & $M_{a v g}$ & $R K_{t} N$ & $R K_{t} N$ & $R K_{t} N$ & \\
\hline 23 & 59.0 & & & & & & & & & & \\
\hline 46 & 66.0 & 23 & 34.5 & 5.9 & 0.7 & 4.0 & 61.0 & & & & \\
\hline 69 & 66.0 & 23 & 57.5 & 7.6 & 2.5 & 3.0 & 64.5 & 5.15 & 7.0 & 10.0 & 40.1 \\
\hline 92 & 72.0 & 23 & 80.5 & 9.0 & 5.8 & 6.0 & 69 & 22.3 & 16. & & 33.9 \\
\hline 115 & 76.0 & 23 & 103.5 & 10.2 & 10.9 & & & 25.9 & & 29 & 29.9 \\
\hline 138 & 79.5 & 23 & 126 . & 11.2 & 17.8 & 3. & & 35.2 & 39 & 42.0 & 27.1 \\
\hline 183 & 86.0 & 45 & 160.5 & 12.7 & 32.4 & 6 & 82.8 & 57.3 & 55.0 & 68.0 & 24.0 \\
\hline 252 & 94.5 & 69 & 217 & 14.8 & 69.9 & & 90 & 96.6 & 85 & 104 & 20.6 \\
\hline 321 & 101.0 & 69 & 286.5 & 16.9 & 138.5 & 6.5 & 97.3 & 136.0 & 136.0 & 149.0 & 18.0 \\
\hline 413 & 109.0 & 92 & 367 & 19.2 & 257 & 8.0 & 105.0 & 216 & 199 & 234 & 15.9 \\
\hline 504 & 115.0 & 91 & 459 & 21.4 & & & 112 & 268 & 30 & 29 & 14.2 \\
\hline 595 & 121.0 & 91 & 550 & 23.5 & 710 & & 118 & 401 & 391 & 363 & 13.0 \\
\hline 687 & 126.3 & 92 & 641 & 25.3 & 1,040 & 5.3 & 123.7 & 471 & 401 & 377 & 12.0 \\
\hline 778 & 129.3 & 91 & 733 & 27.1 & & & & 379 & & 439 & 11.2 \\
\hline & 131.2 & 81 & 819 & 28.6 & & & 130 & 348 & 348 & 441 & 10.6 \\
\hline 1,031 & 132.5 & 172 & 945 & 30.8 & 2,750 & 1.3 & 131.9 & 160 & 133 & 344 & 9.9 \\
\hline 1,260 & 132.8 & 229 & 1,146 & 33.9 & 4,450 & 0.3 & 132.7 & 45 & 73 & 148 & 9.0 \\
\hline
\end{tabular}

$D_{m}$ is determined from the value of the abscissa at which the extrapolated straight line intersects the volume frac-

TABLE 2

\section{Sample Calculation for Distilled Water}


tion equal to 1 . It should be noted that this procedure does not predict the maximum drop size present in the spray but does give an accurate estimate of the surface area of the drops above $40 \mu$ in diameter.

The specific surface area of the spray is the sum of the specific surface for drops up to $40 \mu$ corrected by extrapolating to effective fraction equal to 1 and the specific surface area of drops greater than $40 \mu$ estimated by means of Equation (9).

The corrected volume, surface, and size-frequency curves of the spray are obtained by differentiation of the corrected volume-fraction-vs.-diameter curve.

\section{SIZE- SURFACE- AND VOLUME-DISTRIBUTION} CURVES

The data from the series of runs made with water at a spray pressure of 2,000 $\mathrm{lb} . / \mathrm{sq}$. in. with nozzle 0.75 to $60 \mathrm{deg}$. are used to illustrate the method of computation and extrapolating procedures. The physical properties of the air for these runs are viscosity, $1.8 \times 10^{-4}$ poise, and density, $0.0011 \mathrm{~g} . / \mathrm{cc}$.

The quantities $R K_{t} N$ as a function of the drop diameter are calculated for a set of duplicate runs by means of Equations (2) and (3). The original lighttransmission curves of recorder deflection vs. elapsed time from the end of spray are divided into small time increments so that the original curve may be represented by a series of straight-line segments of slope $\Delta M / \Delta t$. Since the deflection of the recorder is linear with the intensity of the light beam, the recorder deflection may be substituted for the light intensity in Equation (3).

The equations for the water runs are

$$
\begin{gathered}
R K_{t} N=\frac{0.1012}{M_{a v g}}\left(\frac{\Delta M}{\Delta t}\right)\left(t_{a v g}\right)^{5 / 2} \\
D=304\left(t_{a v g}\right)^{-1 / 2}
\end{gathered}
$$

The average values indicated in the in the equations for the recorder deflection and the time are the arithmetic average for the particular increment of the curve. The calculations for run $2,039 \mathrm{~A}$, in which 50 cc. of water was sprayed are summarized in Table 2 . The values of $R K_{t} N$ for the duplicate runs are also listed. The dotted line in Figure 5 indicates the relationship between $R K_{t} N$ and the diameter. The size-frequency distribution curve, the solid line, is obtained by dividing the ordinate values of the $R K_{t} N$ curve by the values $R K_{t}$ for the diameters corresponding to the particular ordinate values. The relationships between $R$ and $D$ and $K_{t}$ and $\alpha$ are shown in Figures 6 and 7 respectively $(1,2)$.

The surface-area and volume distribution curves are obtained by multiplying the ordinate values of the sizefrequency curve by the square and cube respectively of the corresponding diameter. The specific surface area of the spray for drops up to $40 \mu$ in diameter is obtained by integrating the surface-area distribution curve and multiplying the result by the quantity $\left(V_{c} \times 10^{-8}\right) / V \rho$. The volume fractions of the spray up to a given drop diameter are obtained by partial integrations of the volume dis-

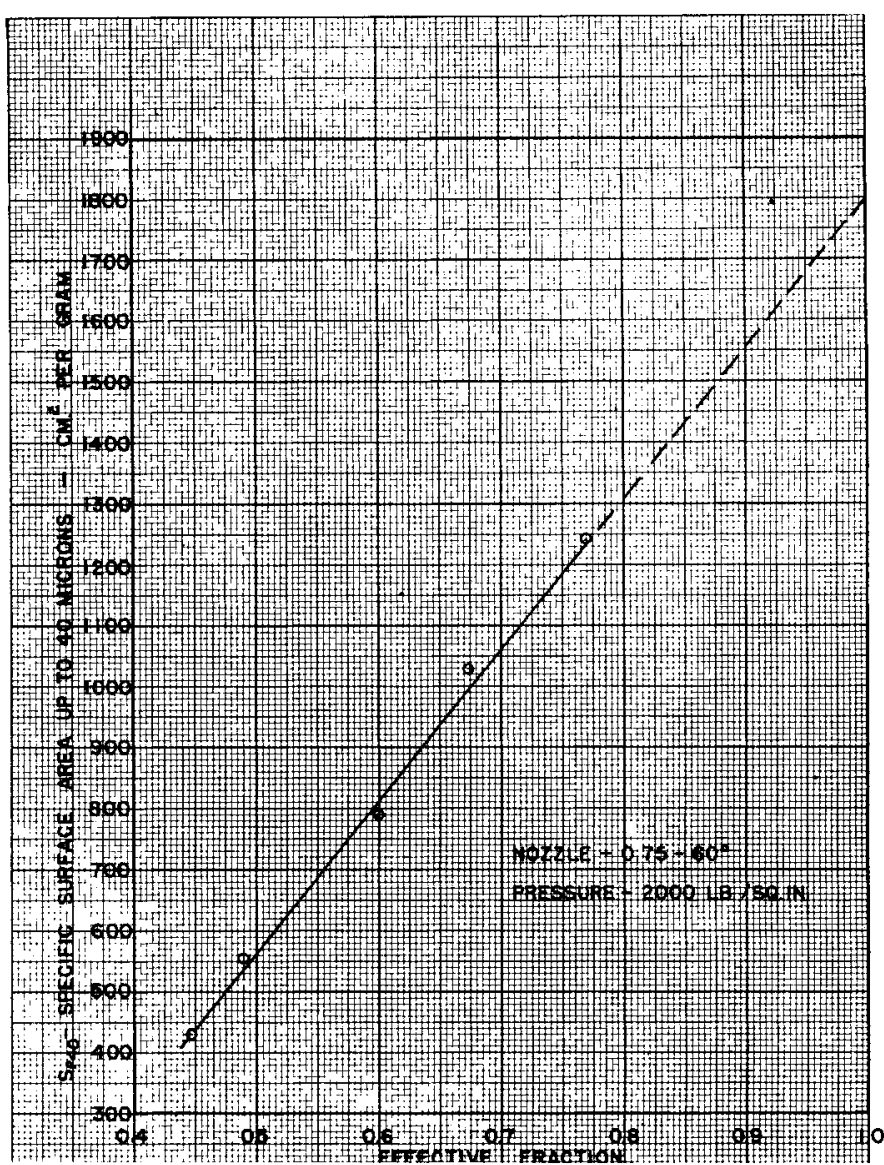

Fig. 8. Specific surface area vs. effective fraction for water spray.

TABLe 3

Summary of Calculation for Distilied Water

Nozzle: 0.75-60 deg. Pressure: 2,000 lb./sq. in.

Volume
sprayed,

300

200

100

75

50

\section{8}

0.00

0.00

0.00

0.00

0.00
0.002

0.002

0.002

10

0.001

0.001

0.009

0.011

0.016

0.024
Volume fractions up to diameter $D, \mu$

$\begin{array}{cc}0.010 & 14 \\ 0.019\end{array}$

16

20

24

0.028

0.047

0.021

0.035

0.062

0.067

0.090

0.027

0.046

0.087

0.130

0.036

0.062

0.116

0.173

0.044

0.072

0.103

0.134

0.196

0.201

0.292
32

$S_{<40}, \quad$ Effective 40 sq. cm./g. fraction

0.110

0.148

0.155

425

0.450

0.205

551

4.485

0.219

0.300

787

0.600

0.288

0.387

1.025

0.675

$\begin{array}{lrr}0.336 & 0.462 & 1,232 \\ 0.485 & 0.665 & 1,800 \\ & S_{>40}= & 406\end{array}$ $S_{>40}=406$
$S=2,206$
0.770

1.000 
tribution curve. The calculations for the series of water runs at $2,000 \mathrm{lb} . / \mathrm{sq}$. in. are summarized in Table 3.

The extrapolation of the specific surface area for drops up to $40 \mu$ to an effective fraction equal to 1 is shown in Figure 8.

A similar plot for the volume fractions taken from Table 3 is shown in Figure 9. The corrected values of the volume fractions up to various diameters, obtained by extrapolation of the curves to an effective fraction equal to 1 in Figure 9 , are tabulated in the last line of Table 3 . The relationship between the corrected volume fraction and reciprocal of the diameter is shown in Figure 10. The dotted-line extrapolation of the straightline region intercepts the volume fraction at unity at a value of $1 / D$ equal to 0.0165 or a value of the maximum diameter $D_{m}$ equal to $60.5 \mu$. The slope of this line $a$ and the constant $b$ are -48.0 and 0.792 respectively. Equation (9) for estimating the specific surface area of drops greater than $40 \mu$ in diameter becomes

$$
\begin{aligned}
S_{>40} & =6 \times 10^{4} e^{0.792} \\
& \cdot\left[e^{-48 / D}\left(\frac{1}{D}+\frac{1}{48}\right)\right]_{40.0}^{60.5}
\end{aligned}
$$

The value of $S_{>40}$ by this equation is 406 sq. cm./g. The specific surface area of the spray, the sum of the corrected specific surface area for drops up to $40 \mu$, and $S_{>40}$ is $2,206 \mathrm{sq} . \mathrm{cm} . / \mathrm{g}$.

The corrected volume-distribution curve, obtained by differentiation of the corrected volume-fraction-vs.-diameter curve of Figure 10 is shown in Figure 11. The corrected surface-area distribution and size-frequency curves, obtained by dividing the ordinate of the curve in Figure 11 by the diameter and the square of the diameter respectively, are shown in Figures 12 and 13. It should be noted that integration of the corrected surface distribution curve in Figure 12 up to $40 \mu$ gives a value of $1,865 \mathrm{sq}$. cm./g., which compares favorably with the value of $1,800 \mathrm{sq}$. cm./g. obtained by direct extrapolation of the specific surface area for drops up to $40 \mu$ from Figure 8 .

The corrected volume fractions and specific surface areas of the sprays for the liquids investigated are summarized in Table 4.

\section{CORRELATION OF DATA}

The specific surface area of the sprays is correlated empirically with the aid of dimensional analysis. For a given nozzle of a specific design it is possible to express the specific surface area as a function of the flow rate, liquid physical properties, and a single parameter for the nozzle. The relationship is of the following form:

$$
S D_{0} \rho=k\left(\frac{q \rho}{D_{0} \mu}\right)^{d}\left(\frac{D_{0} \rho \gamma}{\mu^{2}}\right)^{f}
$$

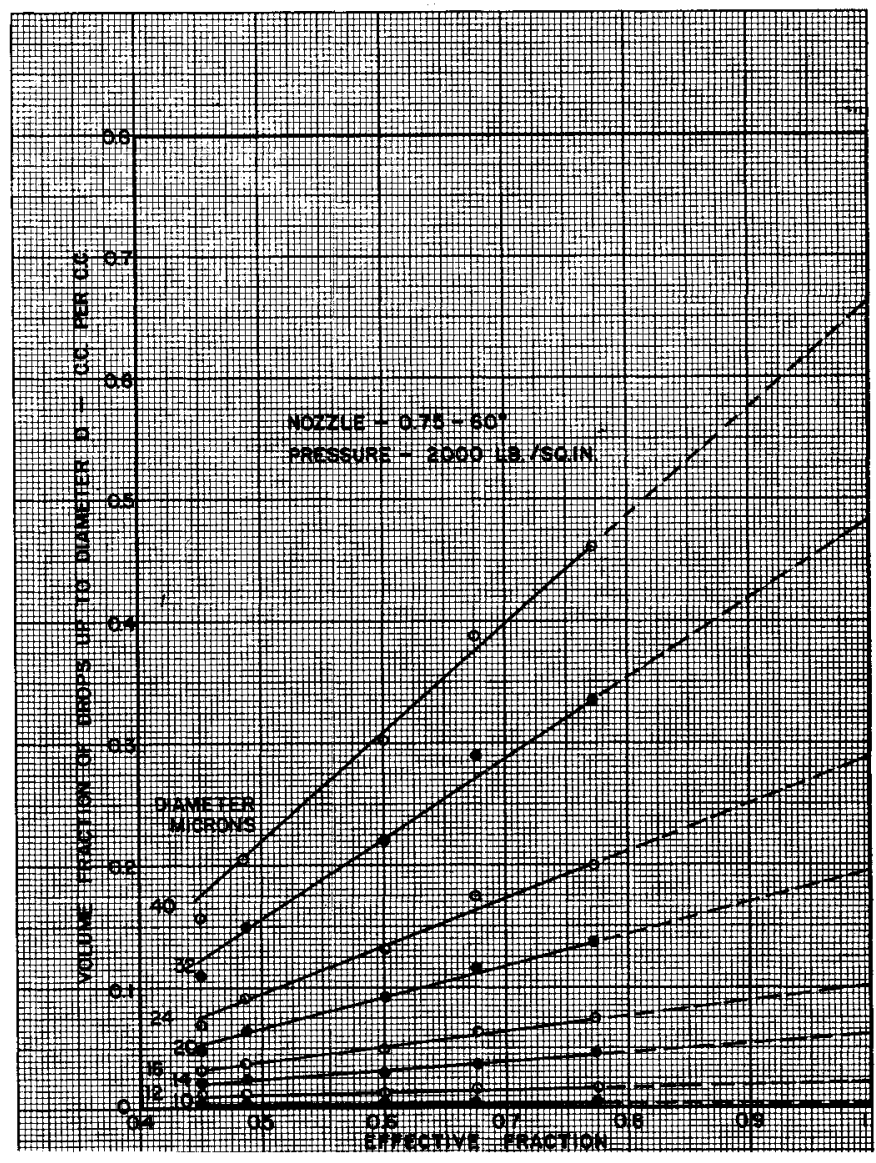

Fig. 9. Volume fraction vs. effective fraction for water spray.

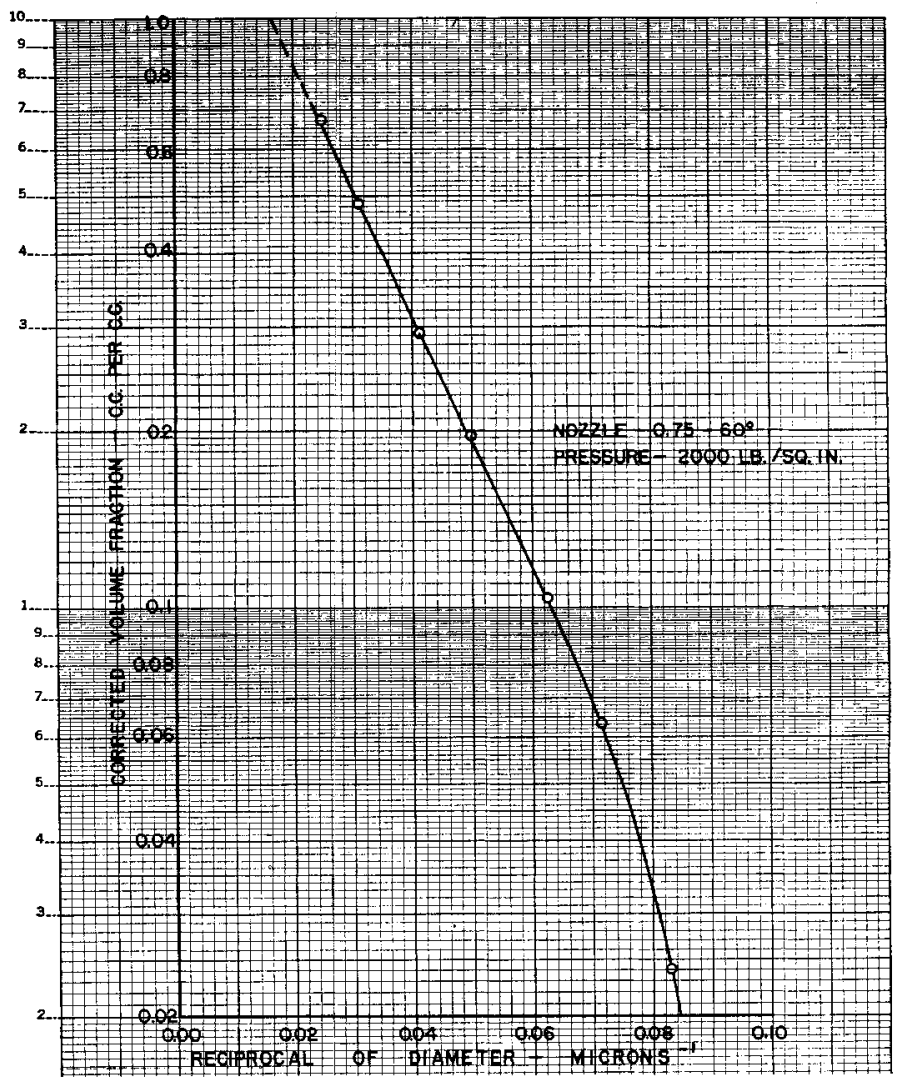

Fig. 10. Corrected volume fraction vs. reciprocal of diameter for water. 


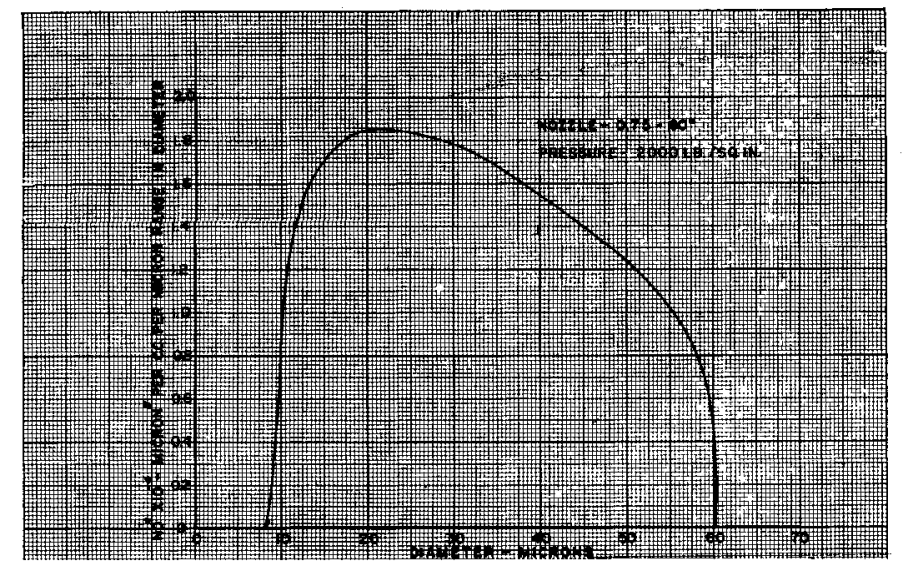

Fig. 11. Corrected volume distribution curve for water.

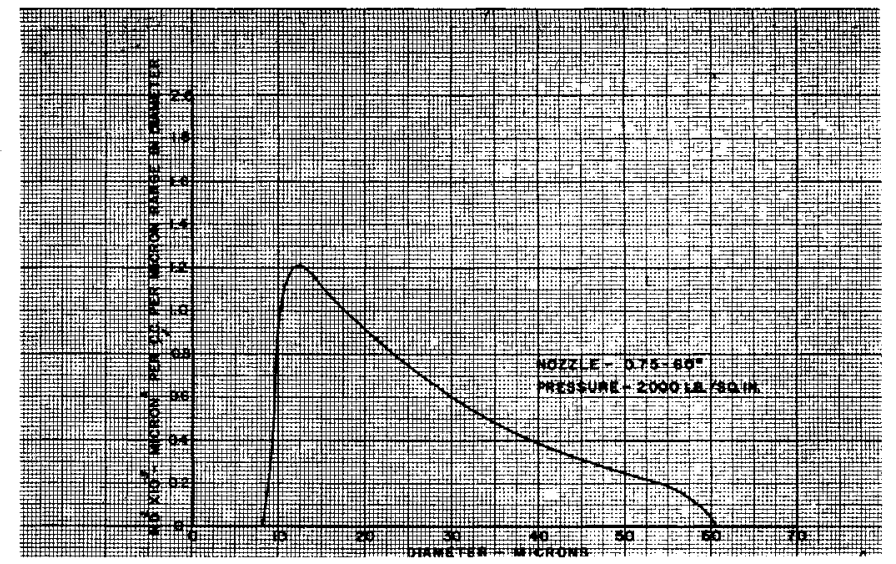

Fig. 12. Corrected surface-area distribution curve for water spray.

TABLE 4

Summary of Corrected Volume Fractions and Specific Surface Areas of Sprays

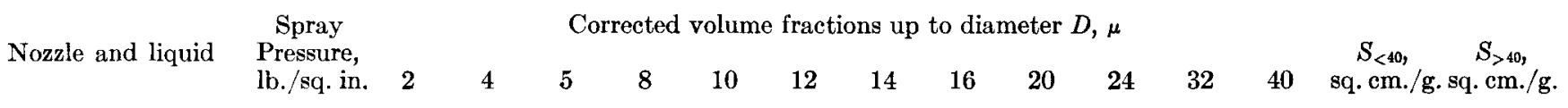

Distilled water

Nozzle- $0.75-30 \mathrm{deg}$.

Nozzle- $-0.75-60 \mathrm{deg}$.

$1,000-1-$
$2,000-$
$2,000-$

$\begin{array}{lllllllll}0.000 & 0.006 & 0.033 & 0.065 & 0.150 & 0.200 & 0.352 & 0.525\end{array}$

1,360

539

Nozzle- $-0.75-80$ deg.

0.00

$\begin{array}{llllllll}0.000 & 0.020 & 0.070 & 0.225 & 0.300 & 0.400 & 0.717 & 0.950\end{array}$

2,500

406

Nozzle $0.75-60 \mathrm{deg}$.

Kerosene

Butyl cellosolve

700

$0.00 \quad 0.0040 .013 \quad 0.035$

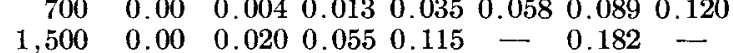

$\begin{array}{llllll}-\quad 0.220 & 0.264 & 0.310 & 0.415 & 0.540\end{array}$

$1,400-\quad-\quad-0.00-0.021-0.0920 .1650 .2300 .4050 .525$

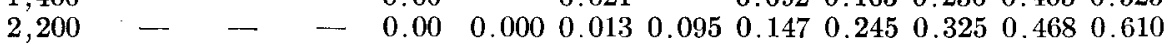

$1,400-0.00 \quad 0.0120 .035-0.100-0.1490 .1930 .2470 .3450 .455$

Ethylene glycol

1,400

- $0.00 \quad 0.0050 .024-0.098-0.1630 .2550 .3350 .4800 .623$

$1,800-0.0060 .0320 .050-0.1200 .167-0.0 .4100 .4950 .60 \quad 0.680$

Diethylene glycol

1,150

0.025

$\begin{array}{lllllll}0.054 & - & 0.070 & 0.094 & 0.110 & 0.140 & 0.190\end{array}$

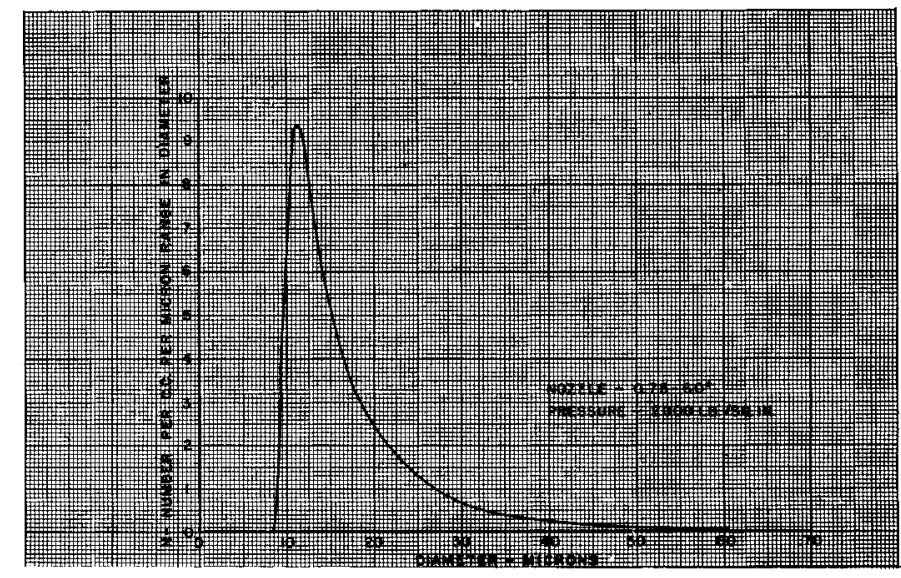

Fig. 13. Corrected size-frequency distribution curve for water.

The volume flow rate is correlated as a function of the pressure drop, viscosity, density, and orifice diameter. The relationship obtained is

$$
\frac{D_{0}{ }^{2} \Delta P \rho}{\mu^{2}}=k^{\prime \prime \prime}\left(\frac{q \rho}{D_{0} \mu}\right)^{g}
$$

The values of the dimensionless groups for Equation (11) are given in Table $5^{*}$ and are plotted in Figure 14.

*Tables 5 and 6 are deposited as document 5300 with the American Documentation Institute, Photo25 D. C and my be obtained for $\$ 1.25$ for photo prints or $35-\mathrm{mm}$. microfilm.
Reynolds number based on the diameter of the nozzle orifice. However, it should be noted that ether procedure is empirical.

The equality of the exponents for the Reynolds number for the surface-area and volume-flow-rate correlations (Figures 14 and 15) leads to the following relation between the compression energy in the fluid supplied to the nozzle and the conversion to surface-area energy:

$$
S \gamma=1.04 \times 10^{-3} \frac{\Delta P}{\rho}
$$




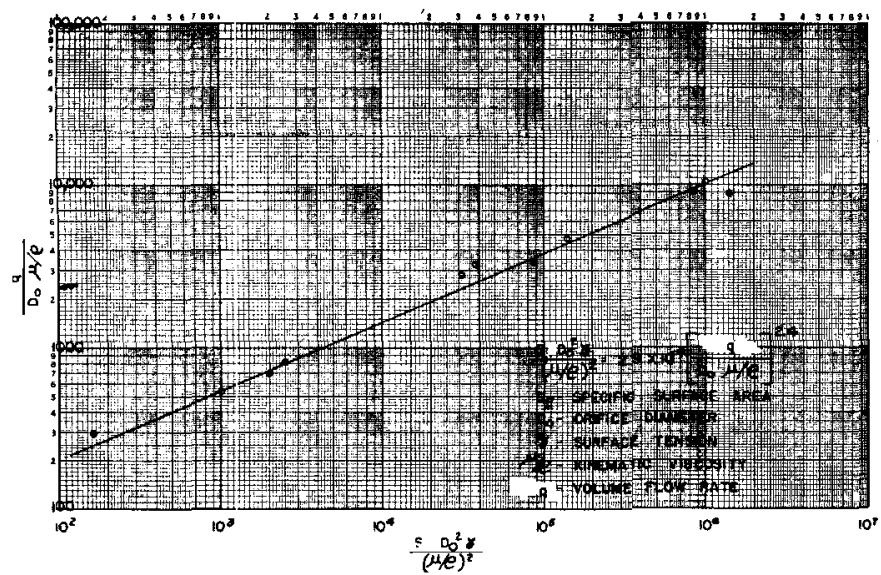

Fig. 14. Correlation of specific surface area and operating variables.

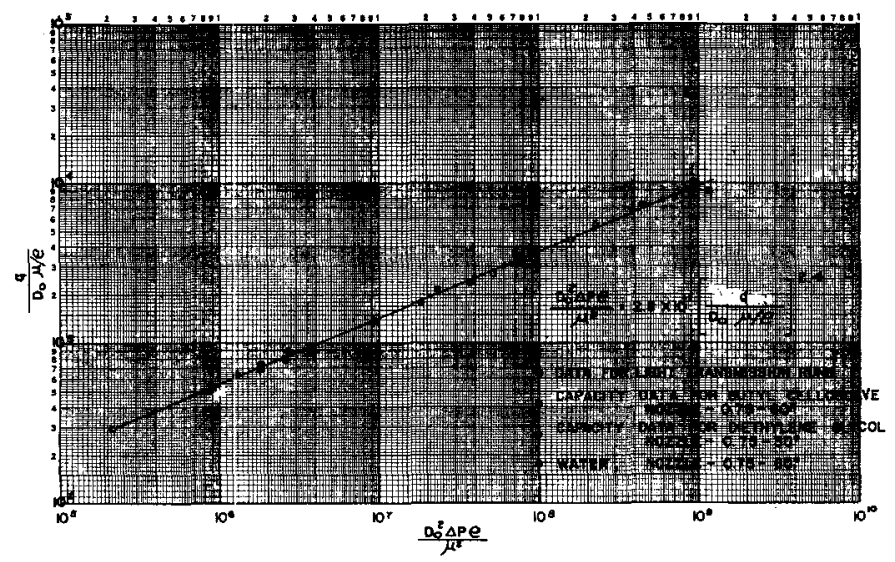

Fig. 15. Correlation of nozzle flow rate and operating variables.

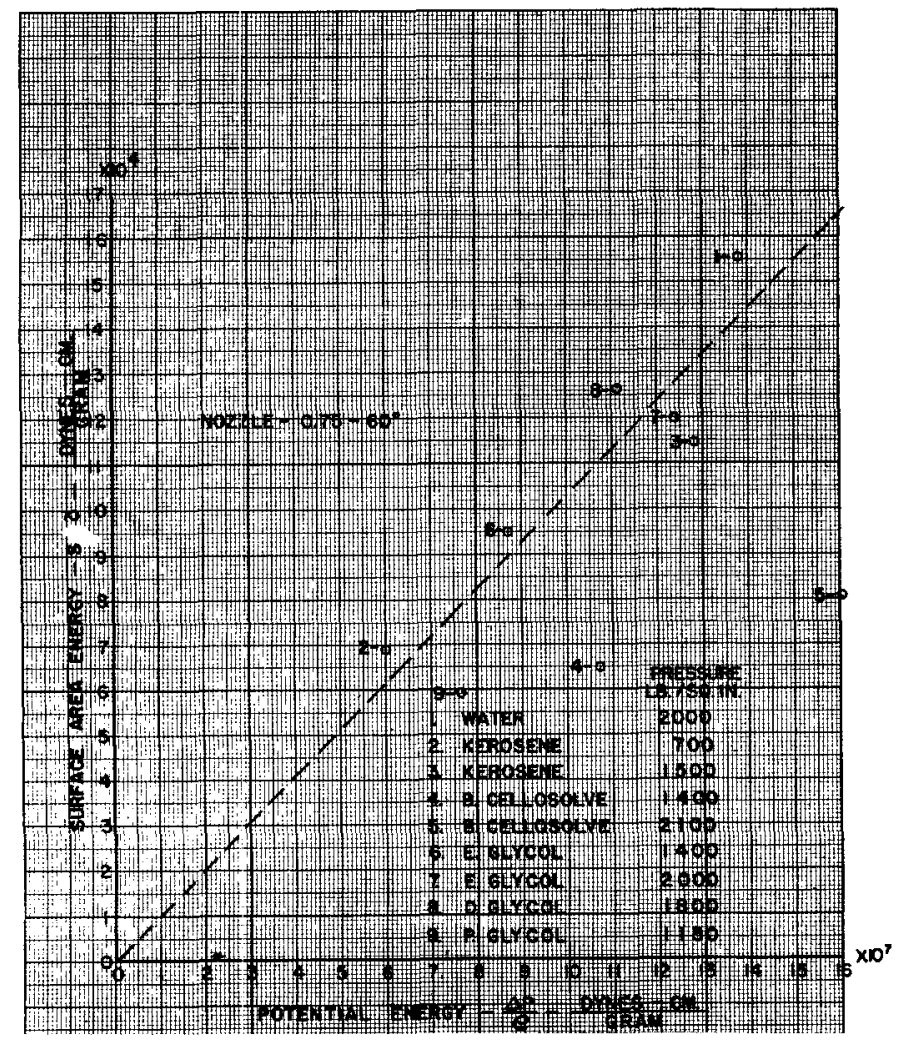

Fig. 16. Conversion of potential energy to surface-area energy.
Equation (13) can be anticipated from the general Bernoulli equation by expressing the kinetic energy and irreversibilities as a fraction of the pressure drop. The data obtained with a nozzle of 0.75 to 60 deg., plotted according to Equation (13), are shown in Figure 16.

\section{RESULTS}

The deviation of the data for nozzle 0.75-80 deg. from the correlation lines in Figures 14 and $15^{-}$-is due to the noncircular shape of the orifice and the difficulty of assigning a correct value for the diameter of the orifice. A high value for the diameter magnifies the error in the surface area and pressure dimensionless groups on Equations 11 and 12. The deviation of the data for the butyl cellosolve sprays from the surface-areacorrelation line in Figure 14 is due to low values of the specific surface area. Additional experiments indicate that the butyl cellosolve vapor reacted with the paint on the interior walls of the spray chamber, which caused the smaller drops to evaporate during the settling period.

The low value of the propylene glycol point is probably due to a low value of the specific surface and represents the limit of the experimental technique for the present equipment. This spray contained such a large percentage of drops greater than $40 \mu$ in diameter that the extrapolations to effective fraction equal to 1 could not be done very accurately. The same difficulty was encountered in attempting to take data for the liquids at flow rates lower than those reported.

An attempt to check the surface-area values obtained from the present study by means of a high-speed photographic technique (13) was not successful. The available equipment could not resolve the droplets because of the high velocity of discharge from the nozzle orifice. Any other method which depends on collecting a sample of the settling spray would necessarily involve corrections similar to those employed in this study.

The effects of the initial humidity in the spray chamber on the size-frequency distribution curves and the corrected volume fractions of the spray obtained by extrapolation to an effective fraction of 1 are shown in Figures 17 and 18 .

The curves in Figure 17 show the relative size-frequency distribution curves obtained for runs in which the same quantity of water was sprayed into the chamber at three different conditions of initial humidity. The upper curve is the result of spraying into the chamber and keeping the door closed between runs, which was the normal experimental procedure; the middle curve of opening the chamber door and turning on a $1 / 4$-in. compressed air line at the top of the chamber for approximately $1 \mathrm{~min}$. 
between runs; the lower curve of opening the chamber door and directing the air stream of an electric fan into the chamber for approximately $3 \mathrm{~min}$. The curves show that the evaporation of the smaller drops is greater the lower the initial humidity. It is seen from the lower curve that the initial humidity was so low that all drops between 8 and $13 \mu$ evaporated completely. Obviously under these conditions it is impossible to extrapolate to effective fraction equal to 1 in order to obtain the true distribution of drops produced by the nozzle.

Figure 18 shows the results of two series of runs at the same conditions except for the initial humidity of the chamber. The solid lines represent runs made at an initial humidity equivalent to the upper curve of Figure 17 and the dotted line equivalent to the middle curve of Figure 17. The volume fractions extrapolate to within $3 \%$ of the same values. These results are believed to be within the range of experimental error. These tests indicate that the closed chamber should be saturated by spraying in order to minimize the loss of drops by evaporation during the spray and settling periods. For small departures from the saturated conditions, the results indicate that the extrapolation of the volume fraction to effective fraction equal to 1 may correct for some of the losses caused by evaporation.

The phenomena of interceptions of small drops by larger drops and the coalescence of smaller drops by diffusion during the differential settling period can give rise to errors in the calculated values of the number of drops from Equation (3). Equation (3) assumes that the removal of the surface area from the light beam at any time is due only to drops leaving the light beam as a result of settling process. If the rate of removal of surface area from the light beam by interception and coalescence is appreciable, it would cause the calculated values of the number of drops to be higher for the larger drop sizes and lower for the smaller drop sizes.

Calculations based on Langmuir's work on interception (5) and Smoluchowski's expression for coalescence (10) indicate that the orders of magnitude of these phenomena for the most concentrated sprays encountered in this study are not serious. For the most concentrated spray produced in this study in terms of drops per unit of volume of dispersion approximation calculations indicate that the interception process causes a rate of removal of surface area of less than $5 \%$ of the rate of removal of surface area by the settling process and for the coalescence phenomena the corresponding value is less than $0.1 \%$.

More important, however, is the fact that the degree of both these phenomena is a function of the product of the concentration of the drops under any interception or coalescence. Thus, decreasing

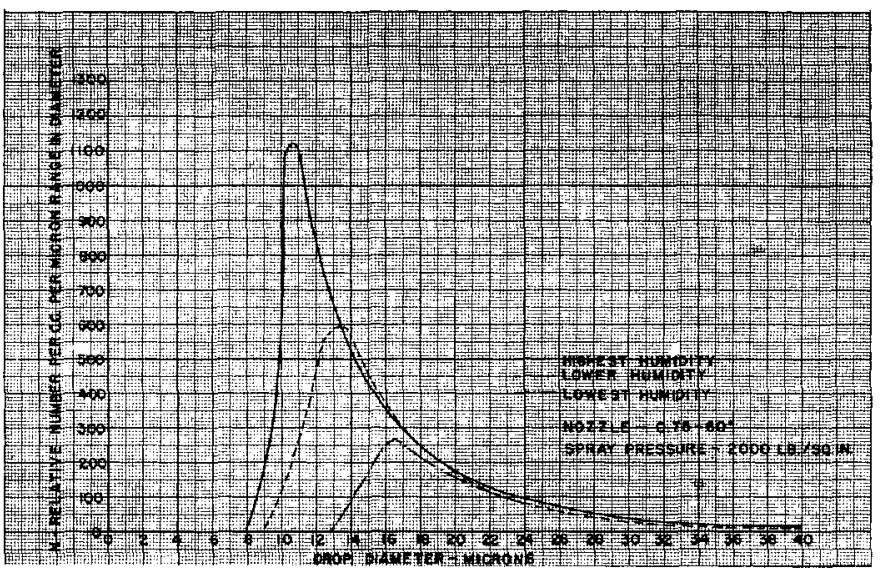

Fig. 17. Size-frequency curves for water at various degrees of initial humidity.

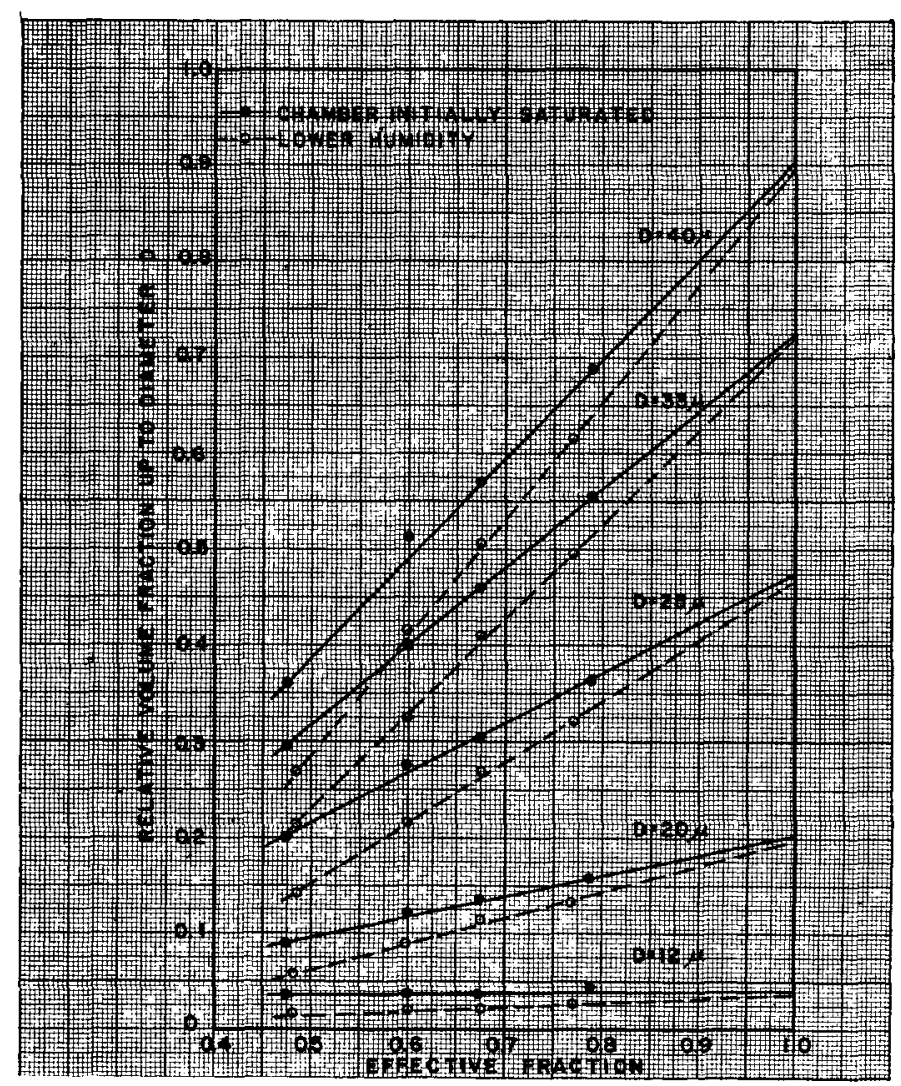

Fig. 18. Comparison of extrapolation for different degrees of initial chamber humidity.

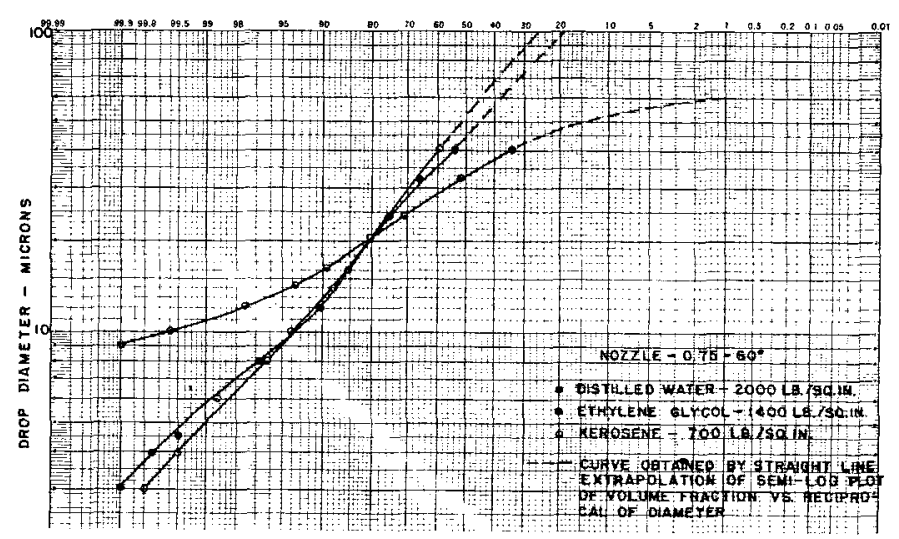

Fig. 19. Logarithmic-probability type of plot of spray data. 
the volume of material sprayed into the chamber and then extrapolating the calculated results to an effective fraction equal to 1 minimizes the effects on these phenomena to a negligible value. This reasoning also applies to the changes in the drop-size distributions that occur during the spray period.

The errors introduced by the convection currents in the transition period following the end of the spray period and the assumption that Stokes's Law is valid from the end of the spray period are difficult to assess quantitatively. It is estimated the use of Stokes's Law results in underestimating the diameter by $3 \%$ in the region of $10 \mu$ and less than $1 \%$ in the region of $5 \mu$. The use of Stokes's Law instead of the StokesCunningham equation for: the smaller drops results in an error of less than $-2 \%$ in the value of the specific surface area for drops up to $40 \mu$.

The use of the Rosin-Rammler (8) and logarithmic-probability equations to estimate the surface area contributed by drops greater than $40 \mu$ yields values for the specific surface area of the sprays which were within $1 \%$ of those obtained by the procedure used in this study. A few typical curves, shown in Figure 19, illustrate the fit of the drop-size distribution data to the log-probability distribution equation.

The quantitative effects of the physical properties of liquids on the specific surface area are in accord with deductions from theoretical considerations (4) which indicate that the drop-size of the spray should increase with surface tension and viscosity or kinematic viscosity. Data reported by Turner and Moulton (12) for grooved-core nozzles indicate that the logarithmic mean diameter varies directly as the 0.813 power of the surface tension and the 0.159 power of the viscosity. For their data the logarithmic diameter is approximately inversely proportional to the specific surface area. Thus the dependence of the specific surface area for their data on surface tension and viscosity is approximately to the -0.7 and -0.2 power, respectively. For the present study the dependence is to the -1.0 and 0.4 power, respectively. The effect of the volume flow rate on the specific surface area appears to be greater for this nozzle than that reported by previous investigators. Data reported by Rupe (9), Lloyd (6), Tate and Marshall (11), and Houghton (4) indicate exponents ranging from 0.3 to 0.80 on the flow rate vs. an exponent of 2.4 for the nozzle used in this study.

\section{ALTERNATIVE FLOW-RATE CORRELATION}

The usual method for correlating flow rate with spray pressure is by means of the nozzle discharge coefficient defined as follows:

$$
K=\frac{4 q}{\pi D_{0}{ }^{2}\left(2 g_{c} \frac{\Delta P}{\rho}\right)^{0.5}}
$$

In terms of the correlation presented above, Equation (12) and Figure 15,

$$
\begin{array}{r}
K=\frac{4}{\pi\left[\left(2.81 \times 10^{-4}\right)\left(2 g_{c}\right)\right]^{1 / 2}} \\
\cdot\left(\frac{q}{D_{0} \mu / \rho}\right)^{-0.2}
\end{array}
$$

Typical values for the discharge coefficient for nozzle 0.75 to $60 \mathrm{deg}$. are given in Table $6 .^{*}$

Since the discharge coefficient varies with the flow rate and the physical properties of the fluid, it is evident that viscous forces are not negligible over the range of variables covered by this study (11).

\section{NOTATION}

$a=$ slope of empirical volume fraction equation $V_{D} / V=e^{(a / D+b)}$

$b=$ intercept of volume fraction equation at point $V_{D} / V=1.0$

$D=$ drop diameter, $\mu$

$D_{m}=$ maximum drop diameter obtained by extrapolation of the corrected volume fraction

$D_{0}=$ orifice diameter of spray nozzle, $\mathrm{cm}$.

$d, d^{\prime}, f, g=$ exponents for dimensionless groups in Equations (11) and (12)

$h=$ settling height from top of spray chamber to center of light beam, cm.

$I=$ intensity of light beam after traversing through a dispersion of drops through a path length of $l \mathrm{~cm}$.

$I_{0}=$ intensity of light beam without a dispersion of drops in the spray chamber

$k=$ Stokes's Law equation constant equal to $\left[18 h / g_{L}\left(\rho_{L}-\rho_{a}\right)\right]^{1 / 2}$

$k^{\prime}, k^{\prime \prime}, k^{\prime \prime \prime}=$ constants in dimensionless equations (11) and (12).

$K_{t}=$ Mie theory total scattering coefficient

$l=$ length of light beam through a dispersion of drops, $\mathrm{cm}$.

$M=$ recorder deflection, a linear function of the light intensity, $I$

$m_{d}=$ mass of liquid that drops out of the spray chamber and onto a removable drawboard at the bottom of the chamber during the spray period

$m_{e}=$ mass of liquid that evaporates from the spray drops during the spray period

$m_{i s}=$ mass of liquid that remains in suspension in the form of drops at the end of the spray period

$m_{s}=$ mass of liquid sprayed

$m_{w}=$ mass of liquid that impinges on the walls of the spray chamber during the spray period

*See footnote on page 424 .
$N=$ derivative with respect to $D$ of the cumulative drop-size distribution function per unit of volume of dispersion, $\mathrm{cm}^{-4}$

$\Delta P=$ spray pressure, $\mathrm{lb} . / \mathrm{sq}$. in.

$q=$ volume flow rate through spray nozzle, cc./sec.

$R=$ correction factor to the total lightscattering coefficient

$S=$ specific surface area of the spray equal to the sum of the extrapolated value of $S_{<40}$ and $S_{>40}$ sq. cm./g.

$S_{<40}=$ specific surface area of spray for drops up to $40 \mu$ obtained by integration of surface-area-frequency curve

$S_{>40}=$ specific surface area of spray for drops greater than $40 \mu$ estimated by means of Equation (9)

$t=$ elapsed settling time from the end of the spray period, sec.

$V_{c}=$ volume of spray chamber, cc.

$V_{D}=$ volume of spray drops up to a diameter $D$, cc.

$V=$ volume of liquid sprayed into the spray chamber, cc.

$\alpha=$ light-scattering-coefficient parameter equal to $\pi D / \lambda$

$\gamma=$ surface tension of liquid, dynes/ cm.

$\lambda=$ wave length of incident light beam, cm.

$\mu=$ viscosity, poise

$\left(\rho_{L}-\rho_{a}\right)=$ density difference between the drops and surrounding medium $\mathrm{g} . / \mathrm{cc}$.

$x=$ fraction of liquid evaporated from spray drops during the spray period

\section{LITERATURE CITED}

1. Gumprecht, R. O. and C. M. Sliepcevich, J. Phys. Chem., 57, 90 (1953).

2. Ibid., p. 95 .

3. -Tables of Light-Scattering Functions for Spherical Particles," Univ. Mich., Eng. Research Inst, Special Publications, Ann Arbor (1951).

4. Houghton, H. G., in "Chemical Engineers' Handbook," ed. by J. H. Perry, 3 ed., p. 1170-1175, McGraw-Hill Book Company, Inc., New York (1950).

5. Langmuir, Irving, Gen. Elec. Research Lab.Rep.RL 140, pp. 51-59, Schenectady, N. Y. (Dec. 31, 1948).

6. Lloyd, P., Proc. Inst. Mech. Engrs. (London), 15, 462 (1945).

7. Mie, Gustave, Ann. Physik, 25, 377 (1908).

8. Rosin, P., and E. Rammler, J. Inst. Fuels, 7, 29 (1933).

9. Rupe, J. H., in "Third Symposium on Combustion and Flame and Explosion Phenomena," The Williams and Wilkins Company, Baltimore (1949).

10. Sinclair, D., "Handbook on Aerosols," chap. 5-8, U. S. Atomic Energy Commission, Washington, D. C. (1950).

11. Tate, R. W., and W. R. Marshall, Jr., Chem. Eng. Progr., 49, 226 (1953).

12. Turner, G. M., and R. W. Moulton, ibid., 49, 185 (1953).

York, J. L., Ph.D. dissertation, Univ. 13. Mich., Ann Arbor (1949). 